Articles 


\section{L'ALTERNANCE POLITICO-RELIGIEUSE DE JUSTINIEN II À LÉON III'}

Dans un premier temps nous rappellerons brièvement ce que nous avons exposé à Copenhague il y a cinq ans ${ }^{2}$ sur la base de documents arméniens, qui jusque là n'avaient pas été pris en considération pour l'histoire de cette période. Nous y adjoindrons ici au début de la même période la portée d'une homélie de Jean Damascène pour les Encénies à Jérusalem, sauvée en géorgien, ${ }^{3}$ et à l'autre bout de la même période, l'homélie de Germain de Constantinople sur les images et la Croix, également préservée en géorgien seulement. $^{4}$

La période de 688 à 720 comporte sept empereurs, sept papes à Rome, cinq patriarches de Constantinople, quatre khalifes à Damas et trois catholicos d'Arménie. Le traité de 688 avec Abd-alMalik, — Justinien II a alors 19 ans, - et la victoire de Thessalonique la même année permettent à l'empereur d'inaugurer sa politique religieuse universelle. Il envoie trente mille hommes en Arménie, Géorgie et Aghouanie. En vrai successeur de Justinien I ${ }^{\text {er }}$, il invite en 689/690 cinq évêques arméniens à Constantinople. N'arrivant pas à un accord de fond, il décide d'entériner seulement les usages chrétiens dans le concile de 691 ou Quinisexte, dont il essayera d'universaliser la valeur en accord avec les Arméniens dans un concile à Theodosiopolis vers 693, dont

${ }^{1}$ Conférence donnée au $\mathrm{XX}^{\mathrm{e}}$ Congrès international des Études byzantines, Paris, 19-25 août 2001. Nous publions le texte comme il a été lu par l'auteur, d'après un fichier de son manuscrit préparé pour ce congrès. Toutes les notes sont introduites par la rédaction.

${ }^{2}$ Il s'agit du XIX ${ }^{\mathrm{e}}$ Congrès international des Études byzantines, Copenhague, 18-24 août 1996. L'auteur a subséquemment publié la conférence qu'il avait donnée

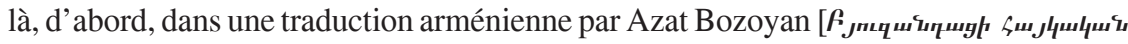

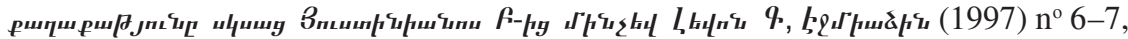
170-180], puis, dans l'original français [La politique arménienne de Byzance de Justinien II à Léon III // Studi sull'Oriente Cristiano 2.2 (1998) 111-120].

${ }^{3}$ Éditée par l'auteur comme: Le discours de Jean Damascène pour la Dédicace de l'Anastasis // OCP 63 (1997) 53-98.

${ }^{4}$ Éditée par l'auteur comme: Un discours inédit de saint Germain de Constantinople sur la Croix et les icônes // OCP 65 (1999) 15-51. Mais maintenant il faut tenir compte de la version slavonne publiée par Vladimir Baranov dans le volume présent [V. A. Baranov, Unedited Slavonic Version of the Apology on the Cross and on the Holy Icons Attributed to Patriarch Germanus of Constantinople (CPG 8033)]. Voir encore une discussion de l'authenticité dans le même article de Baranov. 
les canons sont préservés en arménien, ${ }^{5}$ et non moins avec les Latins, d'abord

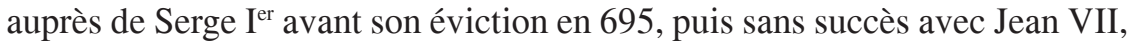
ensuite avec Sissinios au point de s'attaquer à Ravenne, pour finalement réussir après presque trente ans avec le pape Constantin en 711. La ténacité de son entreprise, en dépit de ses dix ans d'éviction, montre quelle valeur il accordait à ce signe de l'unité religieuse chrétienne. Mais de part et d'autre cet accord n'a pas été acquis sans concessions. Le concile de Théodosiopolis entérine pratiquement tous les usages reprochés aux Arméniens dans quelques canons du Quinisexte, et il en va de même pour l'accord avec les Latins. Le concile de Theodosiopolis se garde de parler de Chalcédoine. La légitimité de ce dernier est en effet jalousement maintenue par Justinien II; déjà Justinien ${ }^{\text {er }}$ lui avait témoigné une fidélité inflexible. Le patriarche Kallinikos, qui sacrera les deux successeurs intrus après la mutilation de Justinien II, estime que l'empereur est allé trop loin. Le récit touchant la phialle des bleus construite par Justinien II, et pour laquelle une église dût être détruite, entrâ̂ne une réplique de Kallinikos pleine d'ironie théologique: Gloire au Christ Dieu qui pâtit! Autrement dit, le patriarche considère que les concessions aux Arméniens à Théodosiopolis impliquent une théologie arménienne théopaschite qu'il rejette.

Cette théologie est préservée avec grande éloquence dans le discours du catholicos Sahak III. Le concile de Chalcédoine n'y est pas mentionné, car la théologie avalise le monothélisme et le monoénergisme, rejetés par ceux qui a Constantinople réhabilitèrent Maxime le Confesseur. Sahak traite des natures, des noms, de l'énergie, de la volonté, de la Session à la droite, des bras étendus sur la Croix. Ces thèmes sont repris pour réduire ensuite à l'absurde les opposants. La dernière partie invite à n'adorer Dieu que dans la Croix et non dans les distinctions théologiques de l'homme et de Dieu. En annexe figure un Testament donné à Sembat Bagratouni, qui dit explicitement: Dieu nous a donné comme image la Croix de Dieu à adorer... en effet, toute autre image, Dieu lui-même l'a interdite en disant: Quelle ressemblance vois-tu en moi? Sembat Bagratouni succède à Nerses Kamsarakan, placé à la tête des Arméniens par Justinien II en 689. En 695 ou 697, il fut déporté avec Sahak III à Damas par les Arabes. Il en revint et reçut de Justinien II revenu au pouvoir la permission de se réfugier à Poti, où il demeurera avec les Nakharars arméniens jusqu'en 710 environ. Il accueillit là le spathaire Léon, exilé par Justinien II pour une campagne ossète. C'est grâce aux Nakharars arméniens que

${ }^{5}$ Voir surtout les travaux de l'auteur: Armenien und die Penthekte // Annuarium Historiae Conciliorum 24 (1992) 78-94; Le discours du Catholicos Sahak III en 691 et quelques dossiers annexes au Quinisexte // The Council in Trullo revisited / Ed. G. Nedungatt, M. Featherstone (Rome, 1995) (Kavovıкó 6) 323-454; Justinian II. im Synaxar und das Konzil in Trullo // Annuarium Historiae Conciliorum 27/28 (1995/ 1996) 103-108. 
ce Léon put regagner Constantinople vers 711, où il deviendra en 717 Léon III. La doctrine qu'il défendra face à Germain de Constantinople est exactement celle décrite par Sahak III dans ce Testament.

Le premier à remplacer Justinien II en 695 est Leontios, le général que Justinien avait envoyé en Arménie dix ans auparavant. Un bleu remplace un bleu. A la suite de la perte de l'Afrique en faveur des Arabes, Tibère Apsimaros, cette fois un vert, prend le pouvoir 698, et est pareillement couronné par Kallinikos. Tibère envoie une expédition punitive contre les 30.000 soldats restés fidèles à Justinien II en Arménie, et à n'en pas douter au concile de Théodosiopolis. En 711, Vardan Philipikkos renversa Justinien II et l'exécuta. Il y eut à ce moment un anathème contre Sembat, lequel aurait pillé la ville de Poti le jour de Pâques. Ils auraient enlevé les trésors de l'Église et les auraient emportés dans leur pays. Manifestement, le futur Léon III s'est retiré du Caucase à ce moment. Vardan-Philippikos chassa les Arméniens et les Arabes les établirent dans la région de Mélitene. Or, Vardan-Philipikkos pratiqua une politique ouvertement anti-chalcédonienne, anathématisant le concile de 680, ce que personne avant lui n'avait fait, au point de supprimer une représentation du sixième concile dans le Palais impérial. Ceci, ni Justinien II, ni Sahak III, ni Sembat Bagratouni, ni Léon III ne le firent jamais. Le tour de force du traité de Sahak III était de maintenir la compatibilité avec Chalcédoine et le sixième concile, sans les nommer. Les troupes de l'Opsikion mirent fin au règne de Vardan son règne en 713. Anastase II Artémon qui lui succède a soin de reconnaître officiellement le VIe concile. Théodose III qui lui succède en 713 a été forcé de prendre le pouvoir à son corps défendant, à un moment où déjà le futur Léon III organise l'empire en sous-main.

Après ce bref sommaire, ${ }^{6}$ venons-en à l'homélie du Damascène sur les Encénies.

Bien que le texte soit perdu en grec, son authenticité ne saurait être mise en doute. La vraie question est de savoir en quelle année ce discours d'apparat a été prononcé un 14 septembre dans l'église de l'Anastasis. Nous avons donné une série d'arguments qui militent pour une date précoce. L'absence complète de polémique iconoclaste d'une part, et de l'autre le panégyrique du diacre Épiphane au concile de 787, qui lie la volte-face de Jean Damascène vis-à-vis des richesses des Arabes à la glorification de l'église de la Katholikè, c'est-à-dire de l'Anastasis. D'une part le $\S 16$ de l'homélie montre clairement que les fils d'Agar occupent la surface du temple, d'autre part la coupole de l'Anastasis reçoit une glorification universelle au $\S 30$, laquelle avalise les privilèges théocratiques de l'édifice construit par Hélène et restaurée par Modeste. La Croix prêchée par le Damascène n'est pas celle que

${ }^{6}$ C'est-à-dire, un sommaire de la conférence donnée au congrès de Copenhague dont le résumé se finie ici. 
met en valeur Sahak III. Elle est directement liée à la fois à la coupole de l'Anastasis et à la légitimité théocratique de l'empereur byzantin.

Quand pareille assertion est-elle vraisemblable? La Mosquée sur la surface du temple date déjà de 'Omar al-Khattāb. La vraie question est de savoir si Jean Damascène se serait exprimé comme il le fait après que la Qubbat alSakhr ait été bâtie par Abd-alMalik. Nous pensons que cela n'aurait guère de sens. La base des deux coupoles ne présente qu'une différence de deux centimètres en longueur, et celle du mausolée est évidemment la copie consciente de l'Anastasis plus ancienne. Bien que l'inscription en mosaïques porte la date de 692, on a montré que cette date a été reportée et que l'achèvement de la coupole n'eut lieu sans doute que six ans plus tard, car le Khalife n'eut pas auparavant les loisirs de vaquer à une telle construction. La date a été sciemment assignée avant la date du discours du Damascène. Enfin nous croyons que le Damascène lui-même réagit au concile de 691, où l'empereur Justinien II renoue avec les prérogatives byzantines. Nous voudrions enfin remarquer que la différence entre les deux théologies de la Croix, celle de Sahak avant 691, et celle du Damascène après, permet de comprendre les premières monnaies portant la croix byzantine d'un côté et le Bismillah de l'autre, tandis qu'après cela les monnaies d'Abd-alMalik aboliront la Croix.

Venons-en au dernier volet : l'homélie de Germain de Constantinople où l'opposition à l'iconoclasme revêt encore un caractère presque anodin, eu égard à ce qu'il deviendra dans les trois textes de Germain conservés en grec. L'important dans ce texte est la présence de la Croix, que Léon revendique sans figuration du Christ. La problématique est exactement celle que nous citions plus haut dans le Testament de Sahak III à Sembat Bagratouni. La victoire de 717 sur les Arabes a dès le départ une coloration toute différente d'après qu'on se rallie à Léon III avec la Croix seule ou avec Germain portant l'icône de la Vierge. Cette opposition illustre un nouveau changement politico-religieux introduit par l'empereur byzantin. Un autre indice en est le dialogue qui a incontestablement prit cours entre l'éphémère Khalife Omar II (717-720) et l'empereur Léon, et dont des traces retravaillées sont demeurées en arménien et en arabe. Ce dialogue a d'ailleurs donné lieu finalement à un genre littéraire très fourni, dont les affinités se laissent le plus souvent repérer jusqu'à cette époque.

Le bref raccourci que nous avons donné ici illustre une alternance politico-religieuse qui dépasse largement le cadre des factions du cirque. C'était là le but de notre communication.

Préparé à la publication par Basile Lourié 